\title{
Mechanical changes in the Achilles tendon due to insertional Achilles tendinopathy
}

\author{
Ibrahima Bah ${ }^{1}$, Samuel Kwak ${ }^{1}$, Ruth L. Chimenti, Ph.D. ${ }^{1}$, Michael S. Richards, Ph.D. ${ }^{2}$, John \\ Ketz, M.D. ${ }^{3}$, A. Samuel Flemister, M.D. ${ }^{3}$, and Mark R. Buckley, Ph.D. ${ }^{1}$ \\ ${ }^{1}$ University of Rochester Department of Biomedical Engineering \\ ${ }^{2}$ University of Rochester Department of Surgery \\ ${ }^{3}$ University of Rochester Department of Orthopaedics
}

\section{Abstract}

Insertional Achilles tendinopathy (IAT) is a painful and debilitating condition that responds poorly to non-surgical interventions. It is thought that this disease may originate from compression of the Achilles tendon due to calcaneal impingement. Thus, compressive mechanical changes associated with IAT may elucidate its etiology and offer clues to guide effective treatment. However, the mechanical properties of tissue have not been characterized. Therefore, the objective of this study was to measure the mechanical properties of excised IAT tissue and compare with healthy cadaveric control tissue. Based on the known compositional changes in the Achilles tendon caused by IAT, we hypothesized that the compressive modulus of IAT tissue would be significantly higher than in healthy control tissue and would correlate with symptom severity. We further hypothesized that IAT tendons would exhibit an altered distribution of compressive mechanical properties across the Achilles tendon insertion. Tissue from the Achilles tendon insertion was acquired from healthy donors and from patients undergoing debridement surgery for IAT. Several ( 15) tissue specimens from each donor were then mechanically tested under cyclic unconfined compression at two different loading rates and the acquired data was analyzed to determine the distribution of mechanical properties (secant and tangent compressive moduli and transition strain) for each donor. While the median mechanical properties of tissue excised from IAT tendons were not significantly different than healthy tissue, the distribution of mechanical properties within each donor was dramatically altered. In particular, healthy tendons contained more low modulus (compliant) and high transition strain specimens than IAT tendons, as evidenced by a significantly lower $25^{\text {th }}$ percentile secant modulus and higher $75^{\text {th }}$ percentile transition strain. Furthermore, these parameters were significantly correlated with symptom severity as measured with the VISAA scale. Finally, it was found that preconditioning and slow loading both reduced the secant modulus of healthy and IAT specimens, suggesting that slow, controlled ankle dorsiflexion prior to activity may help IAT patients manage disease-associated pain.

Correspondence to: Ibrahima Bah, Phone: 585-276-4195, Fax: 585-276-1999, ibah@u.rochester.edu.

Publisher's Disclaimer: This is a PDF file of an unedited manuscript that has been accepted for publication. As a service to our customers we are providing this early version of the manuscript. The manuscript will undergo copyediting, typesetting, and review of the resulting proof before it is published in its final citable form. Please note that during the production process errors may be discovered which could affect the content, and all legal disclaimers that apply to the journal pertain. 


\section{Keywords}

Achilles tendon; tendon; compression; insertional Achilles tendinopathy

\section{INTRODUCTION}

Approximately $1 / 3$ of all cases of Achilles tendon pathology involve the tendon-to-bone insertion (Karjalainen et al., 2000) and are classified as insertional Achilles tendinopathy (IAT). IAT causes intense foot pain focused near the heel that is most intense in the morning ("morning stiffness") and is exacerbated by activity (Nelen et al., 1989). While the standard of care for IAT includes a trial of physical therapy, approximately half of patients progress to surgery (Nicholson et al., 2007). In a pilot study, an improved outcome (67\% success) was achieved with a modified eccentric exercise regimen (Jonsson et al., 2008). However, the long-term efficacy of this protocol in a larger cohort is unknown. For the many IAT patients who fail conservative care, operative care for IAT is effective but expensive considering both the cost to the medical care system and to the patient. To minimize risk and cost of care while maximizing function for IAT patients, new conservative care treatments are needed.

Many theories have been proposed regarding the cause of IAT. One hypothesis is that IAT originates from compression of the Achilles tendon-bone insertion against the calcaneus (Almekinders et al., 2003; Cook and Purdam, 2012). Approximately $80 \%$ of patients with IAT have an enlargement of the posterior-superior aspect of the heel known as a Haglund's deformity (Jonsson et al., 2008). During ankle dorsiflexion, this bony protrusion may impinge on the deep side of the tendon near the enthesis and increase local compressive strain. Since compression in known to alter tendon structure and composition and to cause tendon to acquire a more fibrocartilaginous character (Giori et al., 1993; Malaviya et al., 2000; Wren et al., 2000), this abnormal loading environment may contribute to pathology. In fact, a connection between tendon compression and pathology has been made in the supraspinatus tendon of the rotator cuff. Specifically, a rat model was used to show that compression of the supraspinatus tendon (via impingement from the acromion) combined with overuse induces a degenerative state (Soslowsky et al., 2002). In the Achilles tendon, the idea that insertional pathology is caused by impingement is consistent with the finding that IAT tissue undergoes structural and compositional changes consistent with metaplasia into cartilage (Maffulli et al., 2006), a tissue tailored to withstanding compressive forces. In particular, IAT tendons exhibit several hallmark characteristics of cartilage including rounded cells, increased type II collagen and increased glycosaminoglycan (GAG) content. (Note that these are classic markers of several forms of tendon pathology including midportion Achilles tendinopathy (Burssens et al., 2013; Corps et al., 2006; de Mos et al., 2009).) Moreover, $x$-rays reveal calcium deposits in over $70 \%$ of patients diagnosed with IAT (Kang et al., 2012). These progressive tissue alterations into cartilage and bone may represent an adaptation to increased compression.

Although structural and compositional changes associated with IAT have been characterized, it is not known how IAT alters the mechanical response of the Achilles tendon insertion. Since the mechanical changes that accompany IAT may provide clues as to the initiating 
factors and cause of pain in this disease, our objective in this study was to rigorously assess the mechanical properties of IAT tissue and compare with healthy controls. Because the Achilles tendon-calcaneus insertion region experiences large compressive strains due to calcaneal impingement, we focused on the mechanical response of IAT tendon under compression transverse to the direction of alignment. Motivated by previously reported evidence of cartilage formation in IAT tissue (Maffulli et al., 2006), we hypothesized that the compressive modulus of IAT tissue would be higher than in healthy controls and would correlate significantly with symptom severity. We further hypothesized that IAT donor tendons would exhibit a significantly altered distribution of mechanical properties.

\section{METHODS}

\section{Study Design and Specimen Acquisition}

A total of 135 specimens from 9 human donors ( 82 specimens from 5 legs of 4 healthy donors and 53 specimens from 5 legs of 5 subjects with IAT) were used in this study (Tables 1 and 2). Data obtained from both legs of a single healthy donor (subject H1) were pooled together. In IAT patients, the degree of tendon pathology was assessed using the Victorian Institute of Sport Assessment-Achilles (VISA-A) questionnaire, a valid and reliable measure of Achilles tendon severity (Robinson et al., 2001).

Healthy cadaveric tissue was obtained from the Achilles tendon insertion (Figure 1) of donors ranging in age from 69 to 84 (mean age=76) who exhibited no gross signs of insertional Achilles tendon pathology. Pathological tissue was obtained during debridement surgery from the Achilles tendon insertion of subjects ranging in age from 63 to 76 (mean age $=66$ ) as approved by the University of Rochester Research Subjects Review Board. Note that no additional tissue was removed apart from the diseased tissue that is routinely excised as part of the surgical procedure. Dissection of healthy cadaveric tendons was performed to match the surgical procedure used to obtain pathological tissue (Hu and Flemister, 2008). Healthy and IAT specimens were excluded if the donors were known 1) to be pregnant, 2) to be taking medications for HIV, or 3) to have (or have had) prior ipsilateral Achilles surgery or comorbidities (e.g., neuropathic diabetes) that alter tendon characteristics were excluded.

Excised tissue was stored at $-20^{\circ} \mathrm{C}$ prior to testing. To facilitate mechanical testing on specimens with a uniform, simple geometry, following excision from the body and storage in the freezer, tissue was cut transverse to the direction of alignment (which was clearly visible on all excised tissue due to the presence of discernable fibers) into cylinders ( 15 specimens/donor leg) with a target thickness of $1.5 \mathrm{~mm}$ using a $3 \mathrm{~mm}$ diameter biopsy punch (Figure 1). Since excised tissue was transported from the surgery room to the testing laboratory before freezing and obtaining biopsies, it was not feasible to track the exact anatomical location (within the tendon insertion) of each cylindrical specimen. However, a large number of specimens uniformly spread across the insertion were biopsied from each donor to enable evaluation of the distribution of mechanical properties throughout the insertion. Specimens with visible calcification were discarded and not used in the study. The cross sectional area of each specimen was $7.1 \mathrm{~mm}^{2}$. 


\section{Mechanical Testing}

Following dissection, cylindrical tendon specimens were positioned between two flat steel platens in a custom, microscope-mounted mechanical testing device (ADMET, Norwood, MA) that enables simultaneous compression, force measurement and imaging (Figure 2). A small amount of cyanoacrylate glue was used to keep the specimens adhered to the grips. Imaging capabilities were used only to obtain accurate measurements of the initial specimen thickness and to ensure that the specimens did not slip from the grips during testing. A phosphate-buffered saline (PBS) bath surrounded the tested specimens to ensure maintenance of hydration. Unconfined compression was applied along the axial direction of the explant (perpendicular to the direction of tendon alignment) according to the following protocol (Figure 3a): 1) Equilibration to $-0.0050 \mathrm{~N}$ (preloading); 2) 20 cycles of triangle wave compression between the equilibrium position and $-0.10 \mathrm{~N}$ at a rate of $-5.0 \%$ strain/s (fast loading); 3) 2 cycles of triangle wave compression between the equilibrium position and $-0.10 \mathrm{~N}$ at a rate of $-0.50 \% \mathrm{strain} / \mathrm{s}$ (slow loading). (Note that negative forces are compressive while positive forces are tensile.) Despite the fast rate of loading during step 2, the controller for the mechanical testing device was highly effective at limiting the force to its prescribed peak value $(-0.10 \mathrm{~N})$. Specifically, the mean \pm standard deviation peak load across all specimens during fast loading cycles was $-0.099 \pm 0.001$ and during slow loading cycles was $-0.099 \pm 0.001$ (Figure $3 b$ ).

Reflected light micrographs were taken throughout testing and the initial height of each specimen was taken to be the height measured at preload. The heights of healthy and pathological specimens were $1.4 \pm 0.3$ and $1.7 \pm 0.4 \mathrm{~mm}$ (mean \pm standard deviation). Note that the direction of compression of specimens in the testing device is equivalent to the direction of compression due to calcaneal impingement in vivo.

\section{Data Analysis}

The time-dependent strain $\varepsilon(t)$ for steps 2 and 3 of the mechanical testing protocol was obtained by dividing the platen displacement by the initial thickness while the timedependent stress $\sigma(t)$ for these steps was obtained by dividing the measured force by the initial cross sectional area. Time $t=0$ was taken to correspond to the beginning of step 2 . To quantify the mechanical response of the tested specimens during a given cycle, the secant compressive modulus $\mathrm{E}_{\text {secant }}$ was computed by dividing by the peak stress $(-0.10 \mathrm{~N} / 7.1$ $\mathrm{mm}^{2}=-0.014 \mathrm{MPa}$ ) by the peak strain. $\mathrm{E}_{\text {secant }}$ is a gross measure of the resistance to strain in a material that incorporates all portions of the stress-strain curve. The transition strain $\varepsilon_{\text {trans }}$ was calculated as described previously (Connizzo et al., 2013; Dunkman et al., 2013; Lake et al., 2009) as the transition point of a bilinear fit of the nonlinear stress-strain curve for each loading cycle (i.e., the intersection of the pair of lines that optimally fit the stressstrain curve). $\varepsilon_{\text {trans }}$ represents the strain magnitude at which the stress-strain curve begins to steepen (or, equivalently, the absolute value of the strain at which the material begins to "stiffen"). Finally, the tangent compressive modulus $\mathrm{E}_{\text {tangent }}$ was computed from the slope of the second (steeper) line of the bilinear fit. $E_{\text {tangent }}$ is reflective of a material's maximum compressive modulus at high strains. 
For most analyses, $\mathrm{E}_{\text {secant, }} \varepsilon_{\text {trans }}$ and $\mathrm{E}_{\text {tangent }}$ were assessed at a single representative cycle: the final cycle (cycle 20) of fast loading during step 2 of the testing protocol. For these analyses, the prior 19 cycles can be considered as "preconditioning." The distributions of $\mathrm{E}_{\text {secant, }} \varepsilon_{\text {trans }}$ and $\mathrm{E}_{\text {tangent }}$ for each donor and across all donors were computed, and the $25^{\text {th }}$ percentile, $50^{\text {th }}$ percentile and $75^{\text {th }}$ percentile values for each donor were calculated and denoted as $\mathrm{E}_{\text {secant }}{ }^{25 \%}$ (for example). $\mathrm{E}_{\text {secant }}{ }^{25 \%}$ and other analogous parameters were compared across disease state (healthy and IAT) using a ttest. The relationship of disease severity (VISA-A score) with $\mathrm{E}_{\text {secant }}{ }^{25 \%}$ and other analogous parameters was assessed using the Pearson's correlation coefficient.

Note that $\mathrm{E}_{\text {secant }}, \varepsilon_{\text {trans }}$ and $\mathrm{E}_{\text {tangent }}$ are measures of a tendon's resistance to deformation that depend on conditions (e.g., they vary as a function of loading history and loading rate). Thus, the effect of loading history (i.e., preconditioning) on the tendon's resistance to deformation (i.e., $\mathrm{E}_{\text {secant }}$ ) was determined by comparing the median value of $\mathrm{E}_{\text {secant }}$ for each donor $\left(\mathrm{E}_{\text {secant }}{ }^{50 \%}\right)$ for cycles 1 and 20 in step 2 of the loading protocol using a Student's ttest. Similarly, the effect of loading rate was determined by comparing $\mathrm{E}_{\text {secant }}{ }^{50 \%}$ for the final fast loading cycle (cycles 20 in step 2 of the testing protocol) and the final slow loading cycle (cycle 2 in step 3 of the testing protocol, or cycle 22 overall) using a Student's t-test. In this (and all other) statistical comparisons, the threshold for significance was taken to be $\mathrm{p} \leq$ 0.050 .

\section{RESULTS}

For both healthy and IAT specimens, the magnitude of the peak strain (corresponding to a load of $-0.1 \mathrm{~N}$ ) appeared to progressively increase with each loading cycle during step 2 in the testing protocol (Figure 4a). This creep behavior was nearly equilibrated by the $20^{\text {th }}$ cycle.

The highly-nonlinear $|\sigma|(\mathrm{t})$ versus $|\varepsilon|(\mathrm{t})$ curve (for cycle 20) was qualitatively similar for healthy and IAT tissue only at very low compressive strain magnitudes. However, at higher strain magnitudes, the $\sigma(t)$ versus $\varepsilon(t)$ curve appeared to steepen earlier for IAT tissue (Figure $4 \mathrm{~b}$ ). This observation was confirmed by comparing the distribution of the transition strain (i.e., the strain magnitude at which the slope of the stress-strain curve sharply increases) in healthy and IAT tissue (Figure 5a). In IAT tendon specimens, the distribution of transition strains was shifted towards lower values, indicating that most specimens stiffened early in the stress-strain curve. Specifically, while nearly $9 \%$ of healthy specimens had a (compressive) transition strain greater than 30\%, no IAT specimens had a transition strain greater than $30 \%$. Due to this shift in the distribution of transition strains, $\varepsilon_{\text {trans }} 75 \%$ (the $75^{\text {th }}$ percentile transition strain for each tissue donor) was significantly lower in the IAT group as compared with the healthy group, while $\varepsilon_{\text {trans }}{ }^{25 \%}$ and $\varepsilon_{\text {trans }} 50 \%$ were not significantly different between disease states (Figure $5 b$ ). Moreover, $\varepsilon_{\text {trans }}{ }^{75 \%}$ was significantly (positively) correlated with VISA-A score (Figure 5c). Since a lower VISA-A score corresponds to more severe Achilles pathology, this correlation indicates that IAT patients with regions in their Achilles tendons that stiffen early (i.e., at low compressive strains) have greater loss of function. 
The distribution of $\mathrm{E}_{\text {secant }}$ for cycle 20 also exhibited clear differences between healthy and pathological tissue (Figure 6a). Most strikingly, few IAT specimens had low secant moduli. In particular, while more than $20 \%$ of healthy specimens had secant moduli lower than 0.05 $\mathrm{MPa}$, fewer than $4 \%$ of IAT specimen had secant moduli in this range. Therefore, $\mathrm{E}_{\text {secant }}{ }^{25 \%}$ (the $25^{\text {th }}$ percentile secant modulus for each tissue donor) was significantly higher in IAT specimens (Figure 6b). Furthermore, $\mathrm{E}_{\text {secant }}{ }^{25 \%}$ was significantly (negatively) correlated with VISA-A score (Figure 6c). This correlation indicates that IAT patients with compliant (low $\mathrm{E}_{\text {secant }}$ ) regions in their Achilles insertion have less severe pathology. In contrast, the distribution of $\mathrm{E}_{\text {tangent }}$ was not affected by disease state and $\mathrm{E}_{\text {tangent }}{ }^{25 \%}, \mathrm{E}_{\text {tangent }}{ }^{50 \%}$ and $\mathrm{E}_{\text {tangent }}{ }^{75 \%}$ were not significantly altered by IAT (not shown). Taken together, these findings suggest that changes in $\mathrm{E}_{\text {secant }}$ were primarily due to the lower transition strain in IAT tendons, not alterations in the high-strain compressive modulus.

Due to creep, preconditioning reduced the median secant modulus $\left(\mathrm{E}_{\mathrm{secant}}{ }^{50 \%}\right)$ of healthy specimens (Figure 7a). Although $\mathrm{E}_{\text {secent }}{ }^{50 \%}$ was not significantly decreased by preconditioning in IAT specimens $(\mathrm{p}=0.06)$, there was a trend suggesting the possibility of such an effect (Figure 7b). A significant effect of loading rate was observed in both healthy and IAT specimens. In particular, $\mathrm{E}_{\text {secant }}{ }^{50 \%}$ was lower under slow loading than under fast loading (Figure 7c, d).

\section{DISCUSSION}

As hypothesized, insertional Achilles tendinopathy caused significant changes in the compressive mechanical properties of the Achilles tendon insertion. These properties depended on disease state (healthy versus IAT), disease severity, loading history and loading rate. In particular, the distribution of mechanical properties in tissue specimens excised from the Achilles tendon insertion was significantly altered by IAT. IAT specimens were more likely to stiffen at low compressive strains and less likely to exhibit a low compressive modulus. Importantly, VISA-A score-a clinical measure of Achilles tendon pathology that is low in patients with greater loss of function - was 1) significantly (positively) correlated with the number of Achilles tendon regions (i.e., excised specimens) with a low transition strain and 2) significantly (negatively) correlated with the number of regions with a low compressive modulus. Thus, a stiffer (compressive) mechanical response in the Achilles tendon insertion is generally associated with more severe IAT. However, due to viscoelastic/ poroelastic effects, the mechanical response becomes less stiff (lower $\mathrm{E}_{\text {secant }}$ ) after prior cyclic loading (preconditioning) and at slower loading rates.

The increased resistance of IAT tissue to compression is in agreement with the increased glycosaminoglycan (GAG) content of IAT tissue (Maffulli et al., 2006) since GAGs imbibe water, limit fluid flow and reduce permeability in tissues (Giori et al., 1993; Henninger et al., 2010; Lotke and Granda, 1972; Wren et al., 2000) while water provides load support under compression. This finding is also in agreement with the presence of calcium deposits in most IAT tendons (Kang et al., 2012) since increased compressive modulus in IAT specimens may be caused by early-stage calcification that precedes the formation of bony deformities. 
Although the compressive mechanical properties of the pathological human Achilles tendon enthesis have not previously been characterized (to the authors' knowledge), the findings of this study are consistent with other investigations of healthy tendon mechanical properties. For example, the strain rate- and strain-dependent elastic modulus of the bovine Achilles tendon transverse to the direction of alignment measured through ultrasound elastography was found to vary between approximately 10 and $200 \mathrm{kPa}$ for low applied strains ( $<5 \%)$ (Kuo et al., 2001). These findings are comparable to the measured (secant) moduli in this study, which vary between 24 and $124 \mathrm{kPa}$.

This study is not without limitations. First, as described earlier, the parameters assessed through our experimental protocol ( $\mathrm{E}_{\text {secant, }} \varepsilon_{\text {trans }}$ and $\left.\mathrm{E}_{\text {tangent }}\right)$ are dependent on testing conditions (e.g., loading rate). However, according to ongoing ultrasound elastography experiments in our laboratory, the testing conditions used in this study (loading rates of -0.5 or $-5 \%$ strain/second to $\sim 25 \%$ compressive strain) are physiologically relevant and intuitive, allowing for meaningful comparison of the mechanical response of IAT and healthy tendons. Ongoing studies in our laboratory are aimed at gathering and comparing a small set of poroelastic material (intrinsic) properties of healthy and IAT tendon specimens that are independent of testing conditions. These parameters-which include tissue permeability and collagen fiber modulus - will be obtained using inverse finite element analysis on data acquired with a simpler testing protocol (stress relaxation) similar to previous experiments on ligament (Henninger et al., 2010; Weiss and Maakestad, 2006). A second limitation is that fast loading was always performed prior to slow loading, so the decrease in secant modulus measured in both healthy and IAT tendon specimens may instead be due to additional creep. However, creep appeared to be nearly equilibrated prior to slow loading, suggesting that the effect of loading rate was real. A third limitation is that although all specimens (healthy and IAT) were cut to a target thickness of $1.5 \mathrm{~mm}$, a small but significant difference was observed between healthy and IAT specimen thickness $(1.4 \pm 0.3$ versus 1.7 $\pm 0.4 \mathrm{~mm}, \mathrm{p}<1 \times 10^{-5}$ ). However, this was not expected to impact the findings of the study since there was no correlation between specimen thickness and mechanical properties (i.e., $\mathrm{R}^{2}=0.00020$ for $\mathrm{E}_{\text {secant }}$ during the $20^{\text {th }}$ cycle versus thickness across all 82 healthy specimens). Similarly, although healthy and IAT subjects were not age matched, pilot studies on specimens from 10 IAT patients spanning a range of ages from 48 to 76 showed a very weak correlation of $\mathrm{E}_{\text {secant }}{ }^{25 \%}, \mathrm{E}_{\text {secant }}{ }^{50 \%}$ and $\mathrm{E}_{\text {secant }}{ }^{75 \%}$ during the $20^{\text {th }}$ cycle with age $\left(\mathrm{R}^{2}\right.$ $=0.17,0.21$ and 0.066 , respectively). These data suggest that the effects of IAT reported in this study are not simply due to the difference in age between the healthy and IAT groups.

The findings of this study may have important clinical implications. Compression of the Achilles tendon insertion is ubiquitous during ankle dorsiflexion as a result of calcaneal impingement. In IAT patients, the increased compressive modulus of the tendon for fast loading suggests that impingement will deform the tendon less than in healthy patients. Instead, more compressive strain will be taken up by surrounding tissues (fat, skin and bursae). Since these tissues are more enervated than tendon, tendon stiffening (or increase in modulus) and the resulting increased strain outside the tendon are potential causes of pain in patients affected by IAT. However, this study also demonstrates that prior cyclic loading and slow loading reduce the compressive modulus of the Achilles tendon insertion. Thus, "preconditioning" with slow exercises (e.g., slow eccentric loading) is a promising painless 
intervention for IAT patients. Ongoing studies in our laboratory are characterizing in vivo compressive strains in the Achilles tendon insertion of healthy control subjects and subjects with IAT in order to support these theories.

\section{Acknowledgments}

This study was supported by the National Institute of Arthritis and Musculoskeletal and Skin Diseases (NIAMS) of the National Institutes of Health (NIH) under Award Number R03 AR067484 and by a pilot grant funded by NIH/ NIAMS Award Number NIH P30 AR061307. We thank Dr. Joseph Sarver for providing the bilinear fitting code.

\section{References}

Almekinders LC, Weinhold PS, Maffulli N. Compression etiology in tendinopathy. Clin Sports Med. 2003; 22:703-710. [PubMed: 14560542]

Burssens A, Forsyth R, Bongaerts W, Jagodzinski M, Mahieu N, Praet M, Victor J. Arguments for an increasing differentiation towards fibrocartilaginous components in midportion Achilles tendinopathy. Knee Surg Sports Traumatol Arthrosc. 2013; 21:1459-1467. [PubMed: 23001016]

Connizzo BK, Sarver JJ, Birk DE, Soslowsky LJ. Effect of age and proteoglycan deficiency on collagen fiber re-alignment and mechanical properties in mouse supraspinatus tendon. J Biomech Eng. 2013; 135:021019. [PubMed: 23445064]

Cook JL, Purdam C. Is compressive load a factor in the development of tendinopathy? Br J Sports Med. 2012; 46:163-168. [PubMed: 22113234]

Corps AN, Robinson AH, Movin T, Costa ML, Hazleman BL, Riley GP. Increased expression of aggrecan and biglycan mRNA in Achilles tendinopathy. Rheumatology (Oxford). 2006; 45:291294. [PubMed: 16219640]

de Mos M, Koevoet W, van Schie HT, Kops N, Jahr H, Verhaar JA, van Osch GJ. In vitro model to study chondrogenic differentiation in tendinopathy. Am J Sports Med. 2009; 37:1214-1222. [PubMed: 19279223]

Dunkman AA, Buckley MR, Mienaltowski MJ, Adams SM, Thomas SJ, Satchell L, Kumar A, Pathmanathan L, Beason DP, Iozzo RV, Birk DE, Soslowsky LJ. Decorin expression is important for age-related changes in tendon structure and mechanical properties. Matrix Biol. 2013; 32:3-13. [PubMed: 23178232]

Giori NJ, Beaupre GS, Carter DR. Cellular shape and pressure may mediate mechanical control of tissue composition in tendons. J Orthop Res. 1993; 11:581-591. [PubMed: 8340830]

Henninger HB, Underwood CJ, Ateshian GA, Weiss JA. Effect of sulfated glycosaminoglycan digestion on the transverse permeability of medial collateral ligament. J Biomech. 2010; 43:25672573. [PubMed: 20627251]

Hu CT, Flemister AS. Insertional Achilles Tendinopathy: Surgical Options. Oper Tech Orthop. 2008; 18:247-253.

Jonsson P, Alfredson H, Sunding K, Fahlstrom M, Cook J. New regimen for eccentric calf-muscle training in patients with chronic insertional Achilles tendinopathy: results of a pilot study. $\mathrm{Br} \mathrm{J}$ Sports Med. 2008; 42:746-749. [PubMed: 18184750]

Kang S, Thordarson DB, Charlton TP. Insertional Achilles tendinitis and Haglund's deformity. Foot Ankle Int. 2012; 33:487-491. [PubMed: 22735321]

Karjalainen PT, Soila K, Aronen HJ, Pihlajamaki HK, Tynninen O, Paavonen T, Tirman PF. MR imaging of overuse injuries of the Achilles tendon. AJR American journal of roentgenology. 2000; 175:251-260. [PubMed: 10882283]

Kuo PL, Li PC, Li ML. Elastic properties of tendon measured by two different approaches. Ultrasound Med Biol. 2001; 27:1275-1284. [PubMed: 11597369]

Lake SP, Miller KS, Elliott DM, Soslowsky LJ. Effect of fiber distribution and realignment on the nonlinear and inhomogeneous mechanical properties of human supraspinatus tendon under longitudinal tensile loading. J Orthop Res. 2009; 27:1596-1602. [PubMed: 19544524] 
Lotke PA, Granda JL. Alterations in the permeability of articular cartilage by proteolytic enzymes. Arthritis Rheum. 1972; 15:302-308. [PubMed: 4338012]

Maffulli N, Reaper J, Ewen SW, Waterston SW, Barrass V. Chondral metaplasia in calcific insertional tendinopathy of the Achilles tendon. Clin J Sport Med. 2006; 16:329-334. [PubMed: 16858217]

Malaviya P, Butler DL, Boivin GP, Smith FN, Barry FP, Murphy JM, Vogel KG. An in vivo model for load-modulated remodeling in the rabbit flexor tendon. J Orthop Res. 2000; 18:116-125. [PubMed: 10716287]

Nelen G, Martens M, Burssens A. Surgical treatment of chronic Achilles tendinitis. Am J Sports Med. 1989; 17:754-759. [PubMed: 2624286]

Nicholson CW, Berlet GC, Lee TH. Prediction of the success of nonoperative treatment of insertional Achilles tendinosis based on MRI. Foot Ankle Int. 2007; 28:472-477. [PubMed: 17475142]

Robinson JM, Cook JL, Purdam C, Visentini PJ, Ross J, Maffulli N, Taunton JE, Khan KM. Victorian Institute Of Sport Tendon Study G. The VISA-A questionnaire: a valid and reliable index of the clinical severity of Achilles tendinopathy. British journal of sports medicine. 2001; 35:335-341. [PubMed: 11579069]

Soslowsky LJ, Thomopoulos S, Esmail A, Flanagan CL, Iannotti JP, Williamson JD 3rd, Carpenter JE. Rotator cuff tendinosis in an animal model: role of extrinsic and overuse factors. Ann Biomed Eng. 2002; 30:1057-1063. [PubMed: 12449766]

Weiss JA, Maakestad BJ. Permeability of human medial collateral ligament in compression transverse to the collagen fiber direction. J Biomech. 2006; 39:276-283. [PubMed: 16321629]

Wren TA, Beaupre GS, Carter DR. Mechanobiology of tendon adaptation to compressive loading through fibrocartilaginous metaplasia. J Rehabil Res Dev. 2000; 37:135-143. [PubMed: 10850819] 


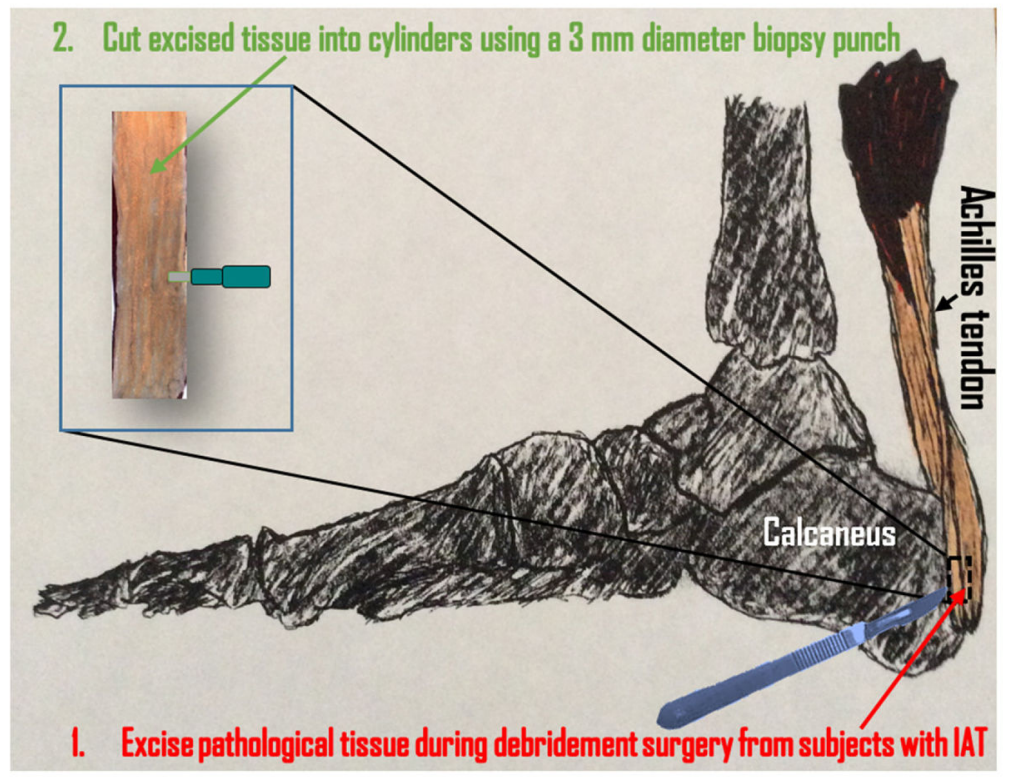

Figure 1. Anatomical location of excised tissue

Pathological tissue was obtained during debridement surgery from subjects with IAT. The inset depicts the deep (anterior) Achilles tendon insertion (i.e., the region of tissue affected by IAT and the area from which specimens were taken). Following surgery and storage at $-20^{\circ} \mathrm{C}$, excised tissue was cut transverse to the direction of collagen alignment into cylinders of thickness $\sim 1.5 \mathrm{~mm}$ using a $3 \mathrm{~mm}$ diameter biopsy punch. Punched specimens were uniformly distributed across the excised tissue. 


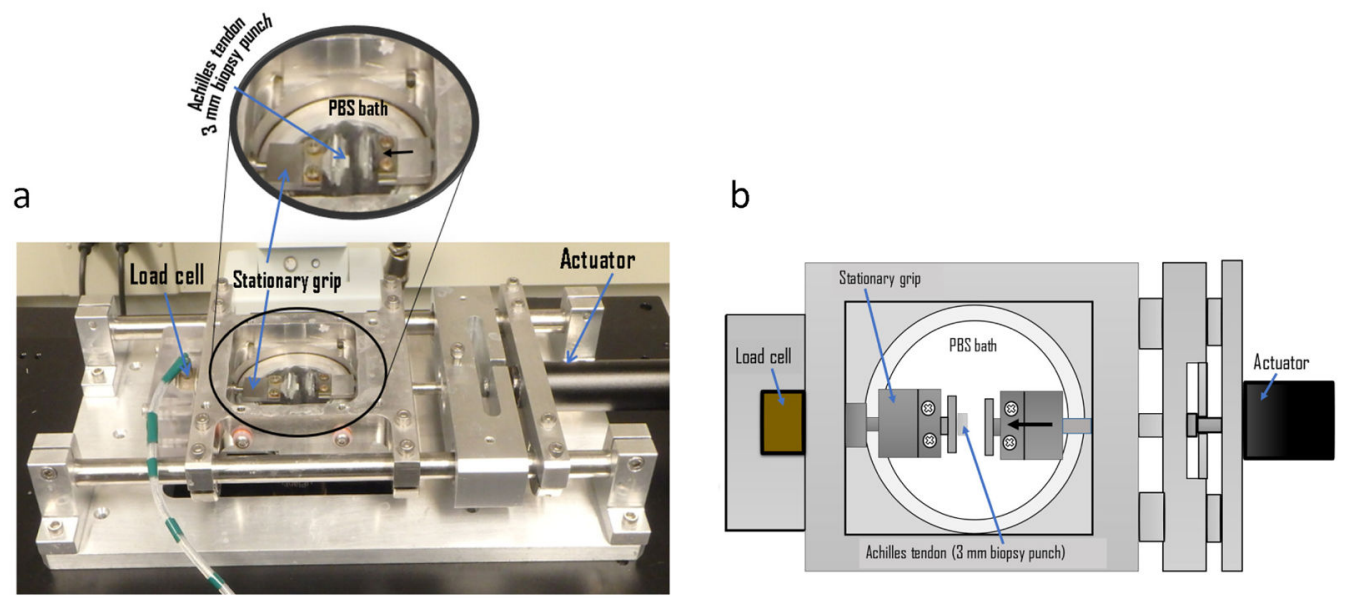

Figure 2.

(a) Compression testing device. Compression testing of excised tissue was conducted in a custom, microscope-mounted mechanical testing device that enables simultaneous compression, force measurement and imaging. (b) Schematic of compression testing configuration. Biopsy punched cylindrical tendon specimens were positioned between two flat steel platens where unconfined compression was applied along the axial direction of the explant (perpendicular to the direction of tendon alignment). A PBS bath ensured maintenance of specimen hydration. 

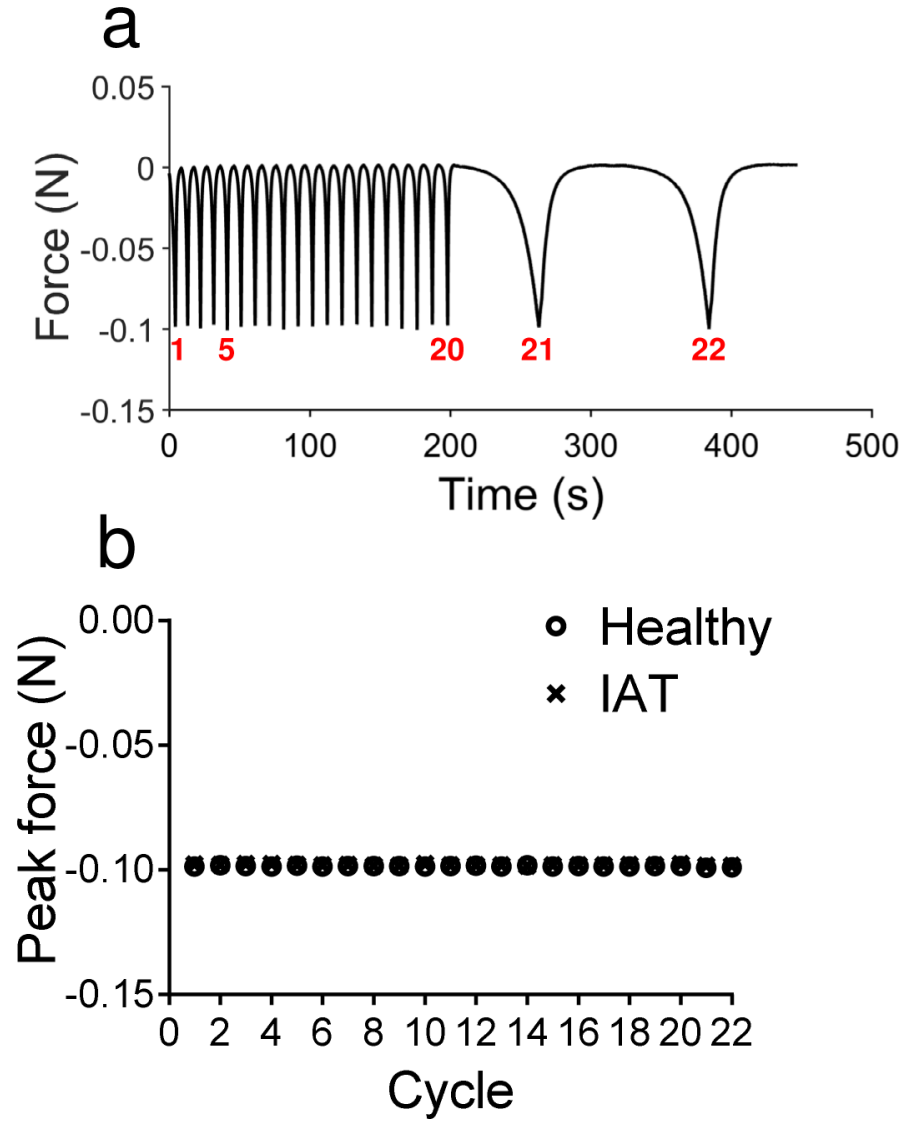

Figure 3.

(a) Loading protocol for a representative specimen showing the applied cyclic force as a function of time. A total of 20 fast loading cycles to $-0.1 \mathrm{~N}$ at $-5 \%$ strain/s precede 2 slow loading cycles to $-0.1 \mathrm{~N}$ at $-0.5 \%$ strain/s. (b) Mean peak force for each cycle in healthy and IAT specimen s. Error bars (representing standard deviation) are shown, but are smaller than the markers for all data points. In all cycle, the controller for the mechanical testing device achieved peak forces very near its prescribed value $(-0.10 \mathrm{~N})$. The mean \pm standard deviation peak load across all specimens during fast loading cycles was $-0.099 \pm 0.001$ and during slow loading cycles was $-0.099 \pm 0.001$. 


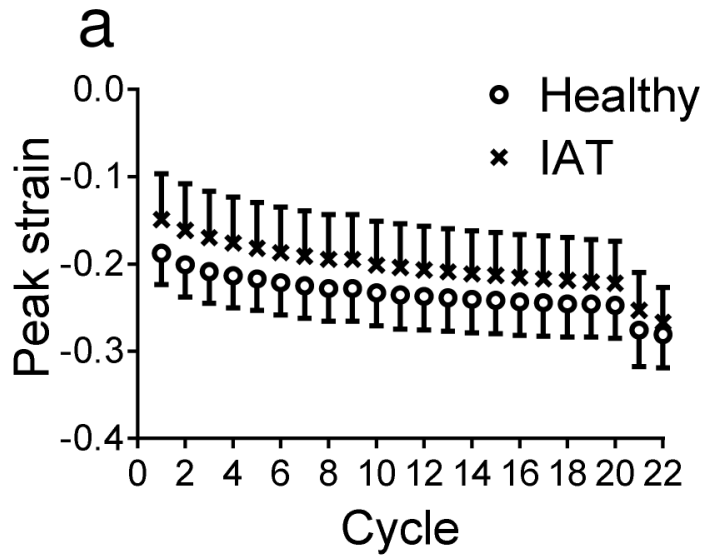

b

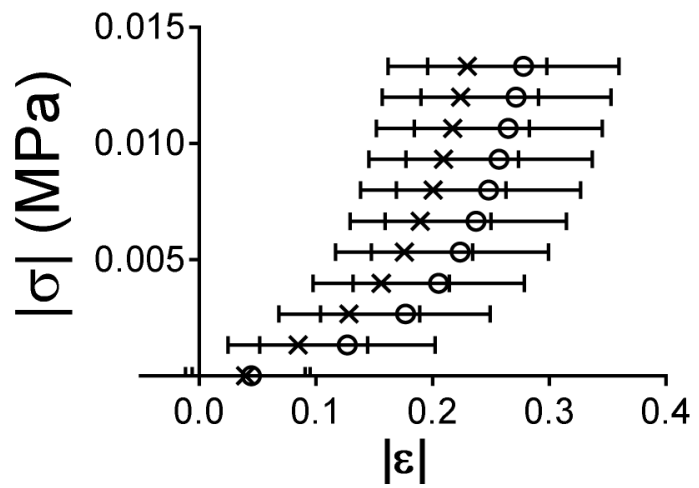

Figure 4.

(a) Peak strain for each loading cycle in healthy and IAT specimens. Due to cyclic creep, the magnitude of the peak strain appeared to grow with each progressive cycle. At cycle 20, the peak strain was approaching its equilibrium value. The strain then dropped precipitously in the slow loading cycles (cycle 21 and 22). Note that most analyses were performed for cycle 20. Data are mean \pm standard deviation. (b) Stress-strain loading curve for healthy and IAT specimens. In cycle 20, the absolute value of the stress appeared to increase sharply at lower compressive strains in IAT specimens than in healthy specimen. Data are mean \pm standard deviation. 

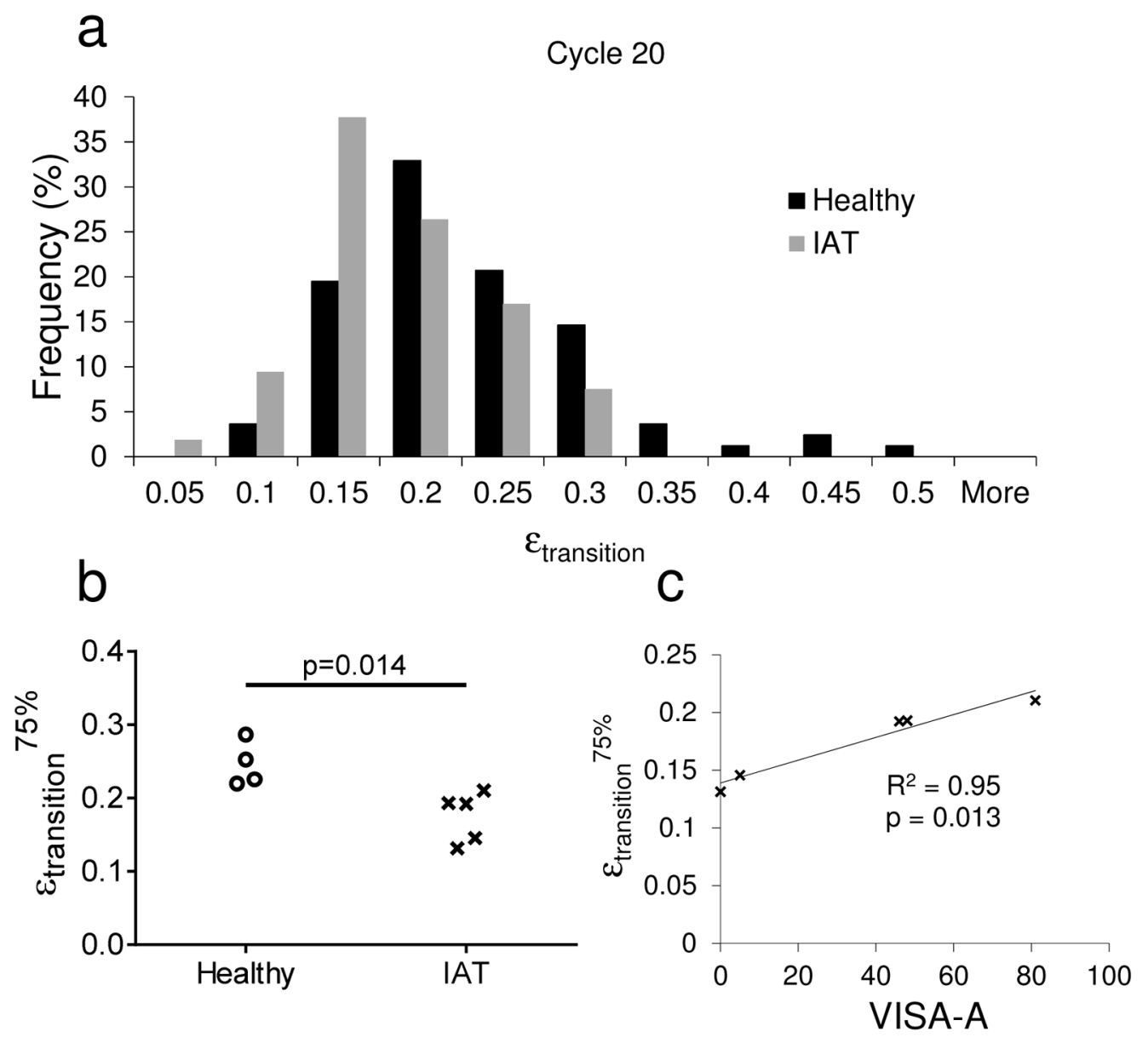

Figure 5.

(a-b) Transition strain distribution for healthy and IAT specimens. (a) In IAT specimens, the transition strain histogram was shifted towards lower values in cycle 20. Thus, (b) a significant decrease in $\varepsilon_{\text {transition }}{ }^{75 \%}$ was observed in the IAT group. (c) Relationship between $\varepsilon_{\text {transition }}{ }^{75 \%}$ and tendon function in IAT patients. $\varepsilon_{\text {transition }}{ }^{75 \%}$ was significantly (positively) correlated with VISA-A score, indicating that donors without high $\varepsilon_{\text {transition }}$ regions in their Achilles tendon insertion had increased disease severity. 


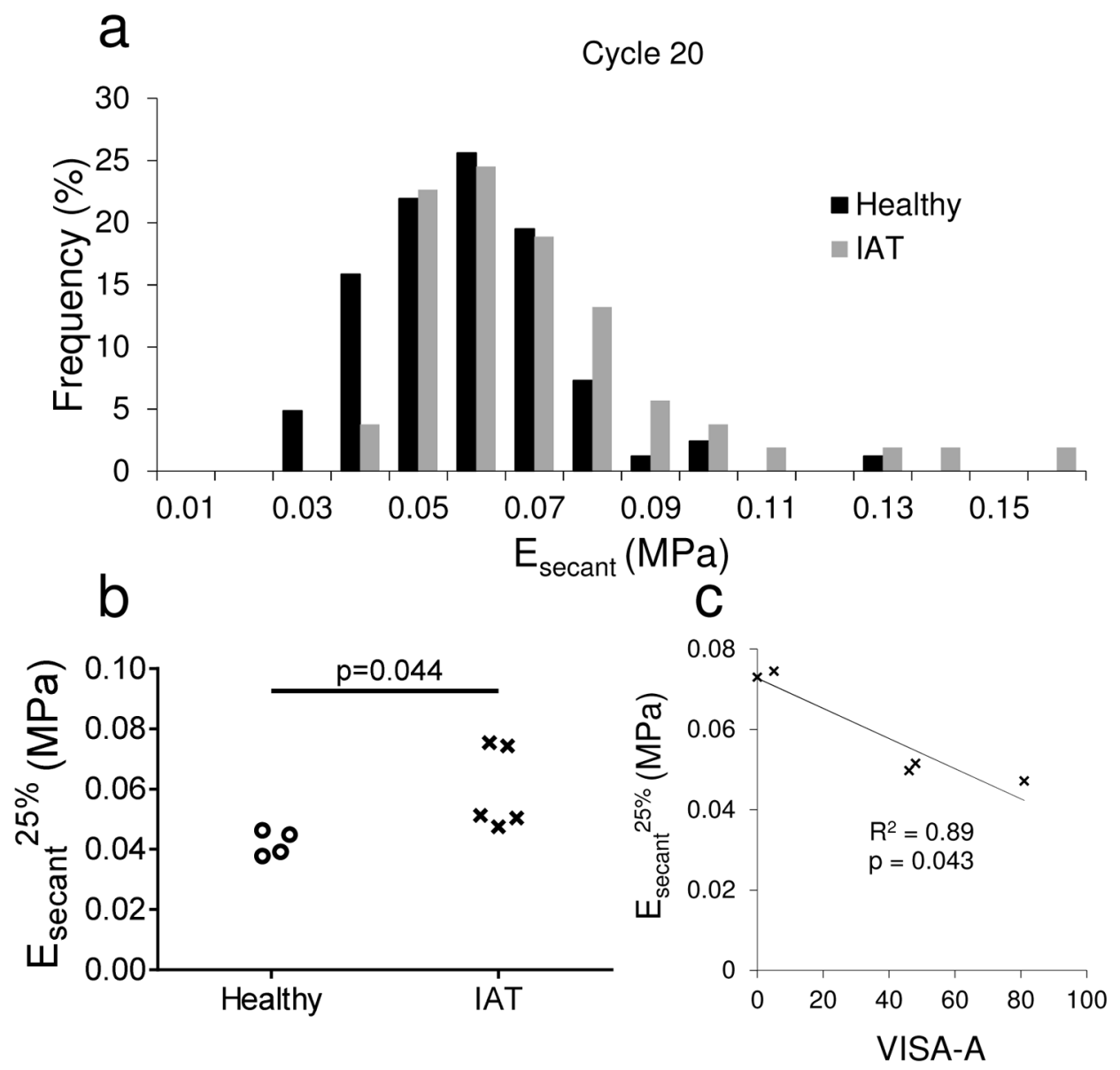

Figure 6.

(a-b) Secant modulus distribution for healthy and IAT specimens. (a) In IAT specimens, the secant modulus histogram was shifted towards higher values in cycle 20. Thus, (b) a significant increase in $\mathrm{E}_{\text {secant }}{ }^{25 \%}$ was observed in the IAT group. (c) Relationship between $\boldsymbol{E}_{\text {secant }}{ }^{25 \%}$ and tendon function in IAT patients. $\mathrm{E}_{\text {secant }}{ }^{25 \%}$ was significantly (negatively) correlated with VISA-A score, indicating that donors without low $\mathrm{E}_{\text {secant }}$ regions in their Achilles tendon insertion had increased disease severity. 


\section{EFFECT OF CYCLIC CREEP}

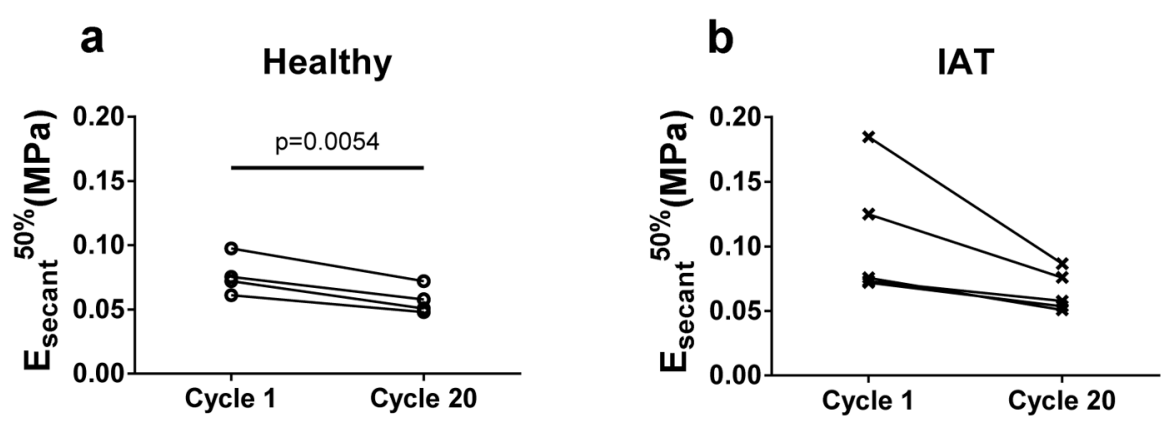

\section{EFFECT OF LOADING RATE}
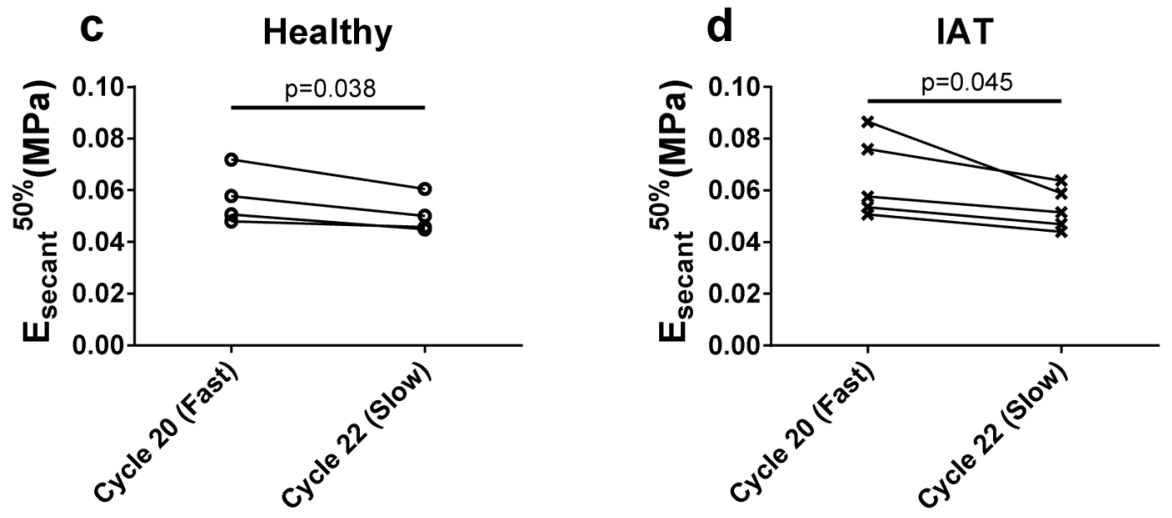

Figure 7.

(a-b) Effect of cyclic creep on median secant modulus. Between cycles 1 and 20, (a) $\mathrm{E}_{\text {secant }} 50 \%$ in healthy specimens decreased significantly while (b) in IAT specimens, there was a trend suggesting the possibility of such an effect $(\mathrm{p}=0.056)$. (c-d) Effect of cyclic creep on median secant modulus. For both (a) healthy and (b) IAT donors, $\mathrm{E}_{\text {secant }} 50 \%$ was lower for slow loading $(-5 \% /$ second $)$ than for fast loading $(-0.5 \% / \mathrm{second})$. 


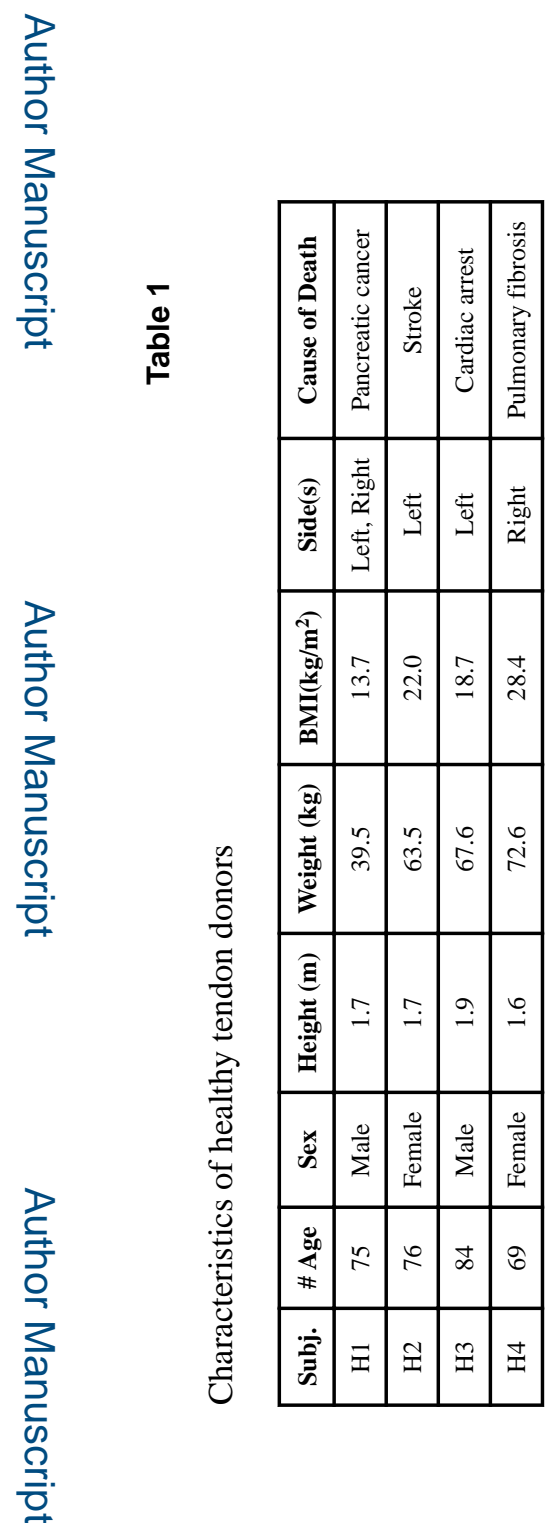

J Mech Behav Biomed Mater. Author manuscript; available in PMC 2017 January 01. 


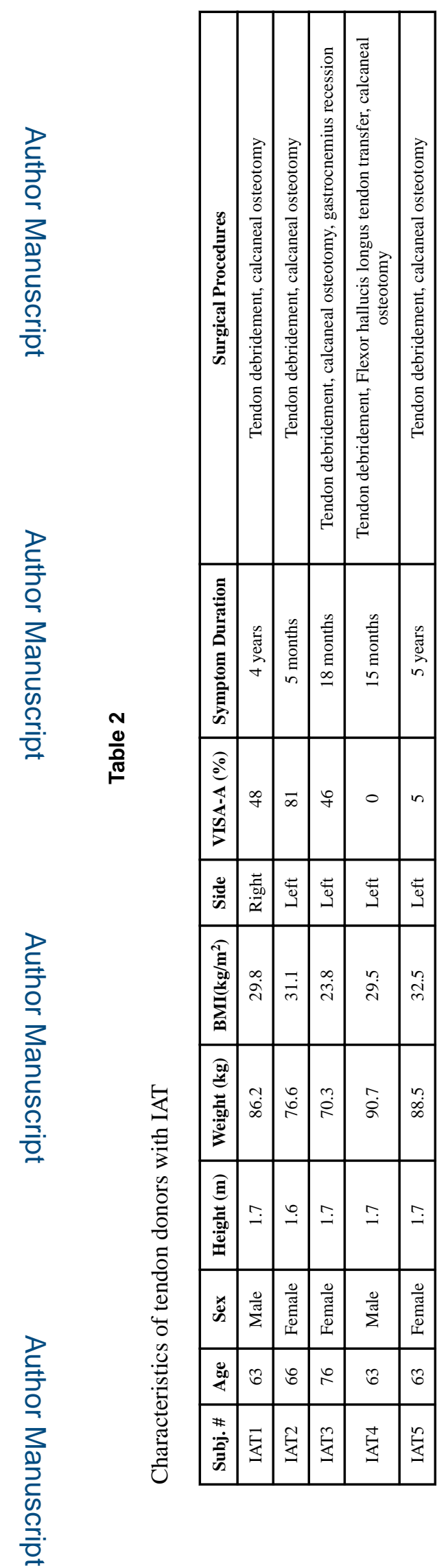

J Mech Behav Biomed Mater. Author manuscript; available in PMC 2017 January 01. 